\title{
Mouse pancreatic ductal organoid culture as a relevant model to study exocrine pancreatic ion secretion
}

\author{
Réka Molnár $\mathbb{1}^{1} \cdot$ Tamara Madácsy ${ }^{1,2} \cdot$ Árpád Varga $\mathbb{C}^{1,2} \cdot$ Margit Németh $^{1,2} \cdot$ Xénia Katona $^{1,2} \cdot$ Marietta Görög $g^{1,2}$. \\ Brigitta Molnár ${ }^{1}$ - Júlia Fanczal ${ }^{1} \cdot$ Zoltán Rakonczay Jr. $^{3} \cdot$ Péter Hegyi ${ }^{4,5} \cdot$ Petra Pallagi ${ }^{1,2} \cdot$ József Maléth $\mathbb{C}^{1,2,6}$
}

Received: 10 May 2019 / Revised: 19 June 2019 / Accepted: 19 June 2019 / Published online: 13 August 2019

(c) United States \& Canadian Academy of Pathology 2019

\begin{abstract}
Pancreatic exocrine secretory processes are challenging to investigate on primary epithelial cells. Pancreatic organoid cultures may help to overcome shortcomings of the current models, however the ion secretory processes in pancreatic organoids - and therefore their physiological relevance or their utility in disease modeling - are not known. To answer these questions, we provide side-by-side comparison of gene expression, morphology, and function of epithelial cells in primary isolated pancreatic ducts and organoids. We used mouse pancreatic ductal fragments for experiments or were grown in Matrigel to obtain organoid cultures. Using PCR analysis we showed that gene expression of ion channels and transporters remarkably overlap in primary ductal cells and organoids. Morphological analysis with scanning electron microscopy revealed that pancreatic organoids form polarized monolayers with brush border on the apical membrane. Whereas the expression and localization of key proteins involved in ductal secretion (cystic fibrosis transmembrane conductance regulator, $\mathrm{Na}^{+} / \mathrm{H}^{+}$exchanger 1 and electrogenic $\mathrm{Na}^{+} / \mathrm{HCO}_{3}{ }^{-}$cotransporter 1) are equivalent to the primary ductal fragments. Measurements of intracellular $\mathrm{pH}$ and $\mathrm{Cl}^{-}$levels revealed no significant difference in the activities of the apical $\mathrm{Cl}^{-} / \mathrm{HCO}_{3}{ }^{-}$ exchange, or in the basolateral $\mathrm{Na}^{+}$dependent $\mathrm{HCO}_{3}{ }^{-}$uptake. In summary we found that ion transport activities in the mouse pancreatic organoids are remarkably similar to those observed in freshly isolated primary ductal fragments. These results suggest that organoids can be suitable and robust model to study pancreatic ductal epithelial ion transport in health and diseases and facilitate drug development for secretory pancreatic disorders like cystic fibrosis, or chronic pancreatitis.
\end{abstract}

Supplementary information The online version of this article (https:// doi.org/10.1038/s41374-019-0300-3) contains supplementary material, which is available to authorized users.

József Maléth

maleth.jozsef@med.u-szeged-hu

1 First Department of Medicine, University of Szeged, Szeged, Hungary

2 HAS-USZ Momentum Epithelial Cell Signaling and Secretion Research Group, University of Szeged, Szeged, Hungary

3 Department of Pathophysiology, University of Szeged, Szeged, Hungary

4 HAS-USZ Momentum Translational Gastroenterology Research Group, University of Szeged, Szeged, Hungary

5 Institute for Translational Medicine and First Department Medicine, Medical School, University of Pécs, Pécs, Hungary

6 Department of Public Health, University of Szeged, Szeged, Hungary

\section{Introduction}

Pancreatic ductal epithelia (PDE) have been known to provide the structural framework of the exocrine pancreas, but more importantly they secrete $\mathrm{HCO}_{3}{ }^{-}$and fluid that play pivotal role in the pancreatic physiology [1]. Exocrine ductal secretion flushes out bioactive molecules, including pancreatic enzymes secreted by acinar cells to the duodenum [2]. In addition, the alkaline ductal fluid neutralizes protons co-secreted during acinar exocytosis, which prevents the premature activation of pancreatic proenzymes in the ductal lumen by inhibiting the autoactivation of trypsinogen [3]. On the other hand, in disease conditions-such as cystic fibrosis or acute pancreatitis - the impaired ductal secretion could lead to the functional and morphological damage of the acinar cells [4, 5], enhanced inflammatory response [6], or complete destruction of the gland leading to exocrine pancreatic insufficiency [7]. Standard isolation techniques of pancreatic ducts [8] — based on digestion of the pancreas with collagenase and manual isolation of the 
ductal fragments under stereomicroscope-have been used extensively to study pancreatic ductal physiology and pathology and led to a better understanding of the ductal epithelia in health and disease. This technique made the study of primary PDE cells possible, including physiologically relevant measurements, such as forskolin induced swelling [5] or fluorescent indicator-based intracellular $\mathrm{pH}$ measurements [9]. The most important limitation of this widely used isolation technique is that the complete removal of the surrounding conjunctive tissue-including fibroblasts -is not possible under a stereomicroscope leading to a mixed culture of epithelial and mesenchymal cells [10]. Thus, for example evaluation of changes in gene expression of epithelial cells could be confounded by alterations in the surrounding fibroblasts. Moreover, due to the limited amount of the isolated tissue, studies of protein expression is limited to immunofluorescent labeling, whereas, the applicability of other techniques to study protein expressions are limited and difficult.

Organoid cultures (OCs) derived from tissue specific Leucine-rich repeat-containing G-protein coupled receptor 5 positive (Lgr5+) adult stem cells emerged recently as novel models of organ development and disease $[11,12]$. By maintaining the activity of $\mathrm{Wnt} / \beta$-Catenin signal transduction cascade-a key driver of most types of tissue stem cells [13]—OCs can be grown in vitro longterm in 3D extracellular matrix-based hydrogels; whereas, epithelial cells in the culture maintain the original cellular diversity and organization of the organ of origin [14]. The technique was originally developed to culture small intestinal Lgr5+ adult stem cells that generated crypt-villus like structures [15]. Since then OCs have been established from a wide range of organs in the gastrointestinal tract, including large intestine and esophagus [11], stomach [16], liver and pancreas [17]. Clear advantages of OCs over conventional 2D cell cultures are that in OCs more relevant cell-to-cell contact is maintained, whereas in 2D cultures the cells are attached to the plastic surface and cell-to-cell contacts are limited to the edges [18]. In pancreatic research currently OCs are studied as relevant human models of tissue development [19] and carcinogenesis [20]. The above described potential limitations of isolated ductal fragments might be overcome by the application of pancreatic OCs for both physiological and pathological studies. However, the physiological relevance of pancreatic OCs is currently not known.

In this manuscript we provide a side-by-side comparison of morphology and function of isolated primary mouse pancreatic ductal fragments and pancreatic OCs. Using endpoint PCR analysis to compare mRNA expressions of 12 functional genes (encoding ion channels and transporters), we demonstrated that both primary ductal fragments and OCs express these genes. Moreover, our data confirmed that epithelial cells in pancreatic OCs maintain apical-basal polarity as demonstrated by electron microscopy and immunolabeling of the apical CFTR $\mathrm{Cl}^{-}$channel, the basolateral $\mathrm{Na}^{+} / \mathrm{H}^{+}$ exchanger 1 (NHE1), and electrogenic $\mathrm{Na}^{+} / \mathrm{HCO}_{3}{ }^{-}$cotransporter 1 (NBCe1). Functional comparison of ion secretion using fluorescent indicators of intracellular $\mathrm{pH}$ and $\mathrm{Cl}^{-}$levels revealed no significant difference in the activities of $\mathrm{Na}^{+}$ dependent basolateral $\mathrm{HCO}_{3}{ }^{-}$uptake, or in the apical $\mathrm{HCO}_{3}{ }^{-}$ extrusion. We also showed that the intracellular $\mathrm{Ca}^{2+}$ signaling - a crucial intracellular signaling pathway in nonexcitable epithelial cells-is highly comparable in primary ductal epithelial cells and OCs cells. Taken together, our data suggest that pancreatic ductal OCs are excellent models to study exocrine pancreatic ductal physiology and pathophysiology.

\section{Materials and methods}

\section{Animals}

Ten- to twelve-week-old FVB/N mice were used with adherence to the NIH guidelines and the EU directive 2010/ 63/EU for the protection of animals used for scientific purposes. The study was approved by the National Scientific Ethical Committee on Animal Experimentation under license number XXI./2522/2018.

\section{Isolation of pancreatic ductal fragments}

Pancreatic ductal fragments were isolated as described earlier [6]. Briefly, after terminal anesthesia the pancreas was surgically removed and digested for $30 \mathrm{~min}$ with $100 \mathrm{U} /$ $\mathrm{ml}$ purified collagenase (Worthington, Cat. No.: LS005273), $0.1 \mathrm{mg} / \mathrm{ml}$ trypsin inhibitor (ThermoFisher Scientific, Cat. No.: 17075029) and $1 \mathrm{mg} / \mathrm{ml}$ bovine serum albumin (VWR, Cat. No.: 9048-46-8) in DMEM Nutirent Mixture F-12 Ham (Sigma, Cat. No.: D6421) at $37^{\circ} \mathrm{C}$ in a shaking water bath. Small intra-/interlobular ducts were isolated by microdissection under stereomicroscope. Isolated ductal fragments were used for experimental analysis, or were cultured as described below.

\section{Mouse ductal pancreatic organoid culture}

For the establishment of OCs we used the previously published protocol by Boj et al. [20]. Briefly, isolated mouse ducts were resuspended in Corning Matrigel (VWR, Cat. No.: 734-1100) and $10 \mu \mathrm{l}$ Matrigel domes were plated into 24-well pates. The plates were placed on $37{ }^{\circ} \mathrm{C}$ until the Matrigel domes solidified. After that prewarmed Mouse Feeding Media was added to each well (for composition of 


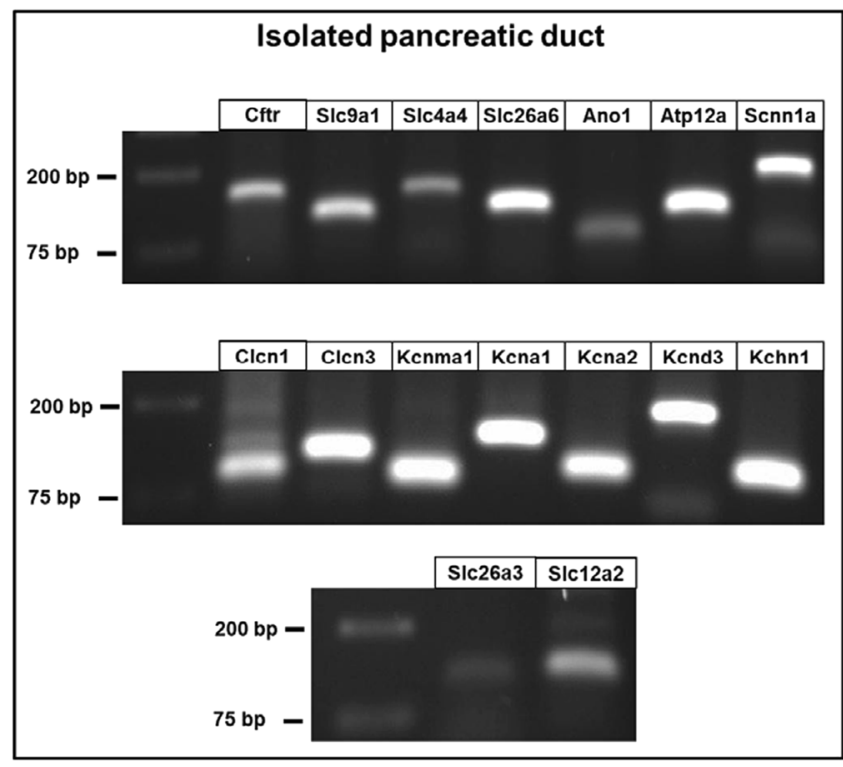

Fig. 1 Comparison of gene expression of isolated pancreatic ducts and pancreatic organoids. Left and right panels show the agarose gel images of cDNA samples derived from isolated mouse pancreatic ductal fragments and pancreatic organoids, respectively. The gene

feeding and digestion media please see Supplementary Table 1). Feeding media was replaced every other day and organoids were passaged weekly by gentle physical disruption and centrifugation. For the experiments organoids were used until passage no. 5. to avoid any changes in gene expression.

\section{Gene expression analysis}

The expression analysis of investigated genes was assessed by combining reverse-transcription (RT-PCR) and conventional polymerase chain reactions (PCR). Total mRNA was isolated from three independent biological replicates of mouse whole brain tissue, mouse ductal fragments, or OCs by NucleoSpin RNA XS kit (Macherey-Nagel, Ref.:740902.50) according to the manufacturer's instructions. The mRNA concentrations were measured by NanoDrop ${ }^{\text {TM }} 2000$ spectrophotometer (ThermoFisher Scientific). $1 \mu \mathrm{g}$ purified mRNA was used for each cDNA synthesis step. RT-PCRs were carried out by using iScript ${ }^{\mathrm{TM}}$ cDNA Synthesis kit (Bio-Rad; Cat. No.: 1708890). For the conventional PCR amplification DreamTaq Hot Start DNA Polymerase (ThermoFisher Scientific, Cat. No.: EP1702) and cDNA specific primers were applied as indicated in Supplementary Table 2. All the primers were validated on template cDNA deriving from mouse brain tissue (Supplementary Fig. 1). To compare gene expression levels derived from the same experiments (which are represented by individual agarose gel images in Fig. 1), we used plot lanes analysis quantification by ImageJ software.

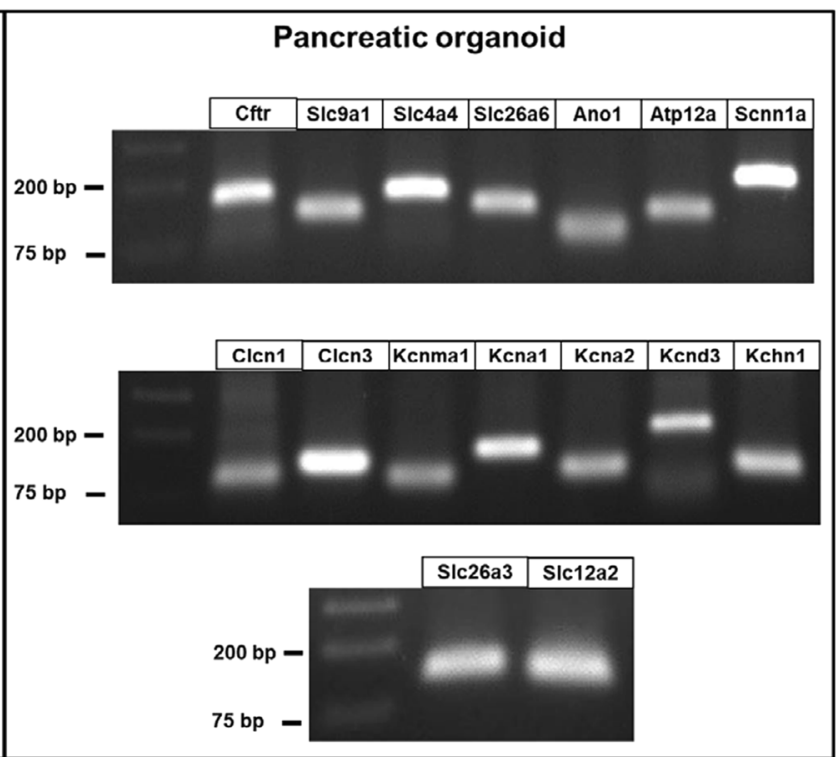

expression of the two samples showed a marked overlap. Images were captured after 35 cycles. List of investigated genes can be found in Supplementary Figure 1

\section{Immunofluorescent labeling}

Isolated pancreatic ductal fragments or organoids were frozen after the first passage in Shandon Cryomatrix (ThermoFisher Scientific, Cat. No.: 6769006) and stored at $-20{ }^{\circ} \mathrm{C}$ until sectioning. $7 \mu \mathrm{m}$ thick sections were cut with cryostat (Leica CM $1860 \mathrm{UV}$ ) at $-20^{\circ} \mathrm{C}$. Sections were fixed in 4\% PFA-PBS for 15 min then washed in $1 \times$ Tris buffered saline (TBS) for $3 \times 5 \mathrm{~min}$. Antigen retrieval was performed in Sodium Citrate - Tween 20 buffer $(0.001 \mathrm{M}$ Sodium Citrate Buffer, pH 6.0 and $0.05 \%$ Tween20) at $94^{\circ}$ $\mathrm{C}$ for $30 \mathrm{~min}$. Sections were blocked with $0.1 \%$ goat serum and $10 \%$ bovine serum albumin (BSA)-TBS for $1 \mathrm{~h}$. Incubation with primary antibodies were performed overnight at $4{ }^{\circ} \mathrm{C}$. For the list and dilution of antibodies, please see Supplementary Table 3. Sections were incubated with secondary antibody for $2 \mathrm{~h}$ at room temperature. Nuclear staining was performed with $1 \mu \mathrm{g} / \mathrm{ml}$ Hoechst33342 (ThermoFisher Scientific; Cat. No.: 62249) for $15 \mathrm{~min}$ and sections were placed in Fluoromount mounting medium (Sigma-Aldrich; Cat. No.: F4680) then left to dry. Images were captured with a Zeiss LSM880 confocal microscope using a $40 \times$ oil immersion objective (Zeiss, NA: 1.4).

\section{Electron microscopy}

\section{Sample preparation}

Isolated pancreatic ductal fragments or organoids after the first passage were fixed for $24 \mathrm{~h}$ in $3 \%$ glutaraldehyde (Electron Microscopy Sciences, Cat. No: 16220) at room 
temperature and washed for $3 \times 15 \mathrm{~min}$ in $0.3 \mathrm{M}$ cacodylate buffer (pH 7.4) (EMS, Cat. No: 12310). For contrasting samples were incubated in $3 \%$ potassium ferrocyanide (Sigma-Aldrich, Cat. No: 60279) and 2\% osmium tetroxide (EMS, Cat. No: 19110) in $300 \mathrm{mM}$ cacodylate buffer for $1 \mathrm{~h}$ at $4{ }^{\circ} \mathrm{C}$. This was followed by $20 \mathrm{~min}$ incubation in $1 \%$ thiocarbohydrazide (Sigma-Aldrich, Cat. No.: 223220), then the samples were placed in $2 \%$ osmium tetroxide for $30 \mathrm{~min}$ at room temperature and finally samples were incubated overnight in $1 \%$ uranyl acetate at $4{ }^{\circ} \mathrm{C}$. Sample dehydration was performed with $20 \%, 50 \%, 70 \%, 96 \%$ and absolute ethanol, respectively for $15 \mathrm{~min}$ in each dilution and 1,2-propylene oxide (Merck, Cat. No.: 8.07027.1001) was used as intermedier $2 \times 5 \mathrm{~min}$. All solutions were prepared with AccuGENE molecular biology water (Lonza, Cat. No.: 51223) and filtered through a $0.22 \mu \mathrm{m}$ syringe filter. For infiltration Epon 812 resin was used according to the manufacturer's instructions (Embed 812 Resin, EMS, Cat. No.: 14900; DDS, EMS, Cat. No.: 13710, NMA, EMS, Cat. No.: 19000, BDMA, Sigma-Aldrich, Cat. No.: 185582). Sample infiltration was performed in two steps (propylene oxide + resin 1:1 solution then pure resin). Resin polymerization was done at $60^{\circ} \mathrm{C}$ for $24 \mathrm{~h}$.

\section{Sectioning and imaging}

Before sectioning, indium tin oxide covered glasses were put into a Quorum carbon coater (Quorum Q150R ES Plus, Quorum Tech) for negative glow discharge. The blocks were trimmed and $100 \mathrm{~nm}$ ultrathin sections were cut by a $35^{\circ}$ Ultra jumbo diamond knife type (DIATOME) on an RMC Powertome ultramicrotome with $0.8 \mathrm{~mm} / \mathrm{s}$ cutting speed. Post contrasting was performed with 5\% uranyl acetate and Reynolds solution. Sections were carbon-coated and placed into a Zeiss Sigma 300 scanning electron microscope (SEM). Images were captured by an in chamber secondary electron detector. Imaging parameters were as follows: 2.34 A filament current, $5 \mathrm{kV}$ acceleration voltage. $30 \mathrm{~nm}$ pixel size was used for lower magnification and 10 $\mathrm{nm}$ for higher magnification images.

\section{Fluorescent microscopy}

Pancreatic ductal fragments or organoids were attached to a poly-1-lysine coated coverglass and were incubated in standard HEPES solution with BCECF-AM $(1.5 \mu \mathrm{mol} / \mathrm{L})$, Fura2-AM $(5 \mu \mathrm{mol} / \mathrm{L})$, or MQAE $(2 \mu \mathrm{mol} / \mathrm{L})$ for $30 \mathrm{~min}$ at $37{ }^{\circ} \mathrm{C}$. Cover glasses were then transferred to a perfusion chamber mounted on an Olympus IX71 inverted microscope. Dye loaded samples were excited with an Olympus MT-20 illumination system equipped with a $150 \mathrm{~W}$ xenon arc light source. For BCECF the filter combination was as follows: $434 / 17 \mathrm{~nm}$ and $497 / 16 \mathrm{~nm}$ single-band bandpass filters for excitation (Semrock; P/N: FF01-434/17-25 and FF01-497/16-25, respectively), $511 \mathrm{~nm}$ edge single-edge standard epi-fluorescence dichroic beamsplitter (Semrock; $\mathrm{P} / \mathrm{N}:$ FF511-Di01-25 × 36) and 537/26 nm single-band bandpass filters for emission (Semrock; P/N: FF01-537/ 26-25). For Fura2: $340 / 26 \mathrm{~nm}$ and $387 / 11 \mathrm{~nm}$ single-band bandpass filters for excitation (Semrock; P/N: FF01-340/2625 and FF01-387/11-25, respectively), $409 \mathrm{~nm}$ edge singleedge standard epi-fluorescence dichroic beamsplitter (Semrock; P/N: FF409-Di03-25 ×36) and $510 / 84 \mathrm{~nm}$ single-band bandpass filters for emission (Semrock; P/N: FF01-510/84-25). For MQAE: $340 / 26 \mathrm{~nm}$ single-band bandpass filters for excitation (Semrock; P/N: FF01-340/ 26-25), $409 \mathrm{~nm}$ edge single-edge standard epi-fluorescence dichroic beamsplitter (Semrock; P/N: FF409-Di03-25 × 36) and $510 / 84 \mathrm{~nm}$ single-band bandpass filters for emission (Semrock; P/N: FF01-510/84-25). The fluorescent signal was captured by a Hamamatsu ORCA-ER CCD camera trough a $\times 20$ oil immersion objective (Olympus; NA: 0.8) with a temporal resolution of $1 \mathrm{~s}$. Ratiometric image analysis was performed by Olympus excellence software.

For pH measurement with SNARF-1 (ThermoFisher Scientific; Cat. No.: C1272), or SNARF-1 dextran (ThermoFisher Scientific; Cat. No.: D3304) organoids were attached to a poly-1-lysine coated coverglass and were incubated in standard HEPES solution with SNARF-1 (10 $\mu \mathrm{mol} / \mathrm{L}$ ) for $30 \mathrm{~min}$ at $37^{\circ} \mathrm{C}$. SNARF-1 dextran was injected into the lumen of the organoids using a glass injection pipette. Images were captured by a Zeiss LSM880 confocal microscope was used with a $\times 40$ water immersion objective (Zeiss, NA: 1.2). Samples were excited with $514 \mathrm{~nm}$ Argon laser and emitted fluorescent signal was captured by a GaASP detector between $550-580 \mathrm{~nm}$ and $610-650 \mathrm{~nm}$ respectively with a temporal resolution of $5 \mathrm{~s}$. The ratio of the two emission wavelengths (640/580 ratio) was calculated by Zeiss Zen Black software.

\section{Statistics}

All data are expressed as means \pm SEM. Significant differences between groups were determined by analysis of variance. $p<0.05$ was considered statistically significant.

\section{Results}

\section{mRNA expression of ion channels and transporters in isolated pancreatic ducts and organoids}

To confirm that OCs are suitable to study pancreatic ductal secretion, first we wanted to check whether gene expression patterns of ion channels and transporter proteins (listed in Supplementary Fig. 1A) are comparable in isolated ducts and 
organoids (cycle number: 35 in Fig. 1; cycle number: 30 in Supplementary Fig. 3). The relative band densities showing the gene expressions compared with each other within one gel are presented in Supplementary Fig. 4. Our results confirmed the expression of Slc26a6, Cftr, Nhel, and Nbcel in both isolated ductal fragments and in pancreatic OCs. In addition, we demonstrated the expression of nongastric $\mathrm{H}^{+} / \mathrm{K}^{+}$ ATPase; $\mathrm{Ca}^{2+}$-activated $\mathrm{K}^{+}$channel (BK channel); Slc26a3 $\mathrm{Cl}^{-}$/anion exchanger and the basolateral $\mathrm{Na}^{+} / \mathrm{K}^{+} / \mathrm{Cl}^{-}$symporter $(N k c c)$. The expression of $\mathrm{K}^{+}$channels in the pancreatic ductal epithelia is controversial and species dependent [21], therefore, we selected four members of the voltage-gated subfamily Kcnal, Kcna2, Kcnd3, and Kcnhl, which were not yet described in the pancreatic ductal epithelia to further confirm the uniformity of gene expression in primary ducts and OCs. We found that these four members of the subfamily are expressed in both samples strengthening their potential similarity. Very interestingly, we also detected the expression of genes coding the two members of the voltage-gated $\mathrm{Cl}^{-}$ channels (Clcn1 and Clcn3), epithelial sodium channel (Enac) and the $\mathrm{Ca}^{2+}$-activated $\mathrm{Cl}^{-}$channel Anoctamin1 (Anol, or Tmem16a) in both isolated primary ductal fragments and pancreatic OCs.

\section{Morphological and functional polarity of pancreatic OCs}

Comparison of the ultrastructure of isolated ductal fragments and pancreatic OCs highlighted that OCs were formed by a single layer of epithelial cells (Supplementary Fig. 5) that show similar apical-basal polarity as primary ductal epithelia (Fig. 2a, b). On the apical membrane, we detected brush border in both samples (arrows), whereas the mitochondria showed similar intracellular distribution around the lumen forming a belt-like structure in the apical segment of the cells (arrowheads) both in OCs and isolated ducts as reported earlier [10]. To investigate the functional polarity immunofluorescent labeling of both the OCs and primary ducts was performed. As demonstrated on the confocal images, we were able to show that NHE1 and NBCe1 are expressed solely on the basolateral membrane whereas CFTR is expressed exclusively on the apical membrane of the epithelial cells (Fig. 2c). Similarly to isolated ducts, these results confirmed the morphological and functional polarity of OCs.

\section{Apical $\mathrm{Cl}^{-}$dependent $\mathrm{HCO}_{3}{ }^{-}$secretion in pancreatic organoids}

As the primary function of the ductal epithelia is ion (especially $\mathrm{HCO}_{3}{ }^{-}$) and fluid secretion, we used standard intracellular $\mathrm{pH}\left(\mathrm{pH}_{\mathrm{i}}\right)$ measurement based on the fluorescent $\mathrm{pH}$ indicator BCECF-AM to estimate the $\mathrm{HCO}_{3}{ }^{-}$efflux across the apical membrane to further confirm the functional similarity of OCs and isolated ducts. Cells were exposed to $20 \mathrm{mM} \mathrm{NH} \mathrm{Cl}_{4} \mathrm{in} \mathrm{HCO}_{3}{ }^{-} / \mathrm{CO}_{2}$-buffered solution from the basolateral side which triggered an immediate increase in $\mathrm{pH}_{\mathrm{i}}$ due to the rapid influx of $\mathrm{NH}_{3}$ across the membrane (Fig. 3a and Supplementary Fig. 7A). This was followed by a slower recovery of the alkaline $\mathrm{pH}_{\mathrm{i}}$ toward the basal value. The recovery depends on the $\mathrm{HCO}_{3}{ }^{-}$efflux (i.e., secretion) from the ductal epithelia via the $\mathrm{SLC} 26 \mathrm{Cl}^{-} / \mathrm{HCO}_{3}{ }^{-}$ exchangers and CFTR [6]. Once $\mathrm{NH}_{4} \mathrm{Cl}$ is removed, the $\mathrm{pH}_{\mathrm{i}}$ drops to the acidic range due to the overshoot of the compensatory mechanisms. Again, this is followed by a slow recovery to reach basal $\mathrm{pH}_{\mathrm{i}}$. This recovery phase depends on activities of the basolateral NHE1 and NBCe1 [6]. The initial rate of recovery from alkalosis and acidosis was measured $(\Delta \mathrm{pH} / \Delta t)$ over the first $30 \mathrm{~s}$ and the base flux $\left[\mathrm{J}\left(\mathrm{B}^{-}\right)\right]$was calculated as previously described [6]. Using this approach, we were not able to show significant differences between primary isolated ductal epithelia and pancreatic OCs, suggesting that apical $\mathrm{Cl}^{-} / \mathrm{HCO}_{3}{ }^{-}$exchange activity and basolateral $\mathrm{HCO}_{3}{ }^{-}$uptake is similar (Fig. 3a, b). In addition, exposure of the cells to $10 \mu \mathrm{M}$ CFTR(inh)172 (a specific inhibitor of CFTR channel) significantly decreased the base flux in both samples, suggesting that the functional activity of CFTR contributes to the recovery in OCs under these conditions (Fig. 3a, c). We also preformed this experimental protocol in HEPES buffered extracellular solution (Supplementary Fig. 6). Under these conditions, only recovery from acid load can be interpreted. This reflects NHE activity, which was significantly higher in isolated ducts.

\section{Indirect measurement of CFTR activity in pancreatic OCs using fluorescent $\mathrm{Cl}^{-}$indicator}

Forskolin-induced swelling (FIS) is currently the state-ofthe-art technique to estimate CFTR activity in 3D OCs [22]. FIS has several advantages (e.g., it is relatively simple and robust allowing precision medicine treatment [22]), but it also has some potential limitations as well (such as the increased intraluminal pressure). In these series of experiments we used an intracellular $\mathrm{Cl}^{-}$ level $\left(\left[\mathrm{Cl}^{-}\right]_{\mathrm{i}}\right)$ sensitive fluorescent indicator MQAE to track $\mathrm{Cl}^{-}$movement to estimate CFTR activity. The fluorescent signal emitted by MQAE inversely correlates with the $\left[\mathrm{Cl}^{-}\right]_{i}$, thus an increase reports $\mathrm{Cl}^{-}$efflux. Removal of extracellular $\mathrm{Cl}^{-}$from the $\mathrm{HCO}_{3}{ }^{-} / \mathrm{CO}_{2}$-buffered solution resulted in a decrease of $\left[\mathrm{Cl}^{-}\right]_{i}$, most likely due to the $\mathrm{Cl}^{-}$efflux from the cytosol via CFTR, which was significantly enhanced by Forskolin administration (Fig. 4). In addition, $10 \mu \mathrm{M}$ CFTR(inh)-172 completely abolished the $\mathrm{Cl}^{-}$extrusion, whereas the protein kinase A (PKA) inhibitor H-89 significantly impaired it to the 

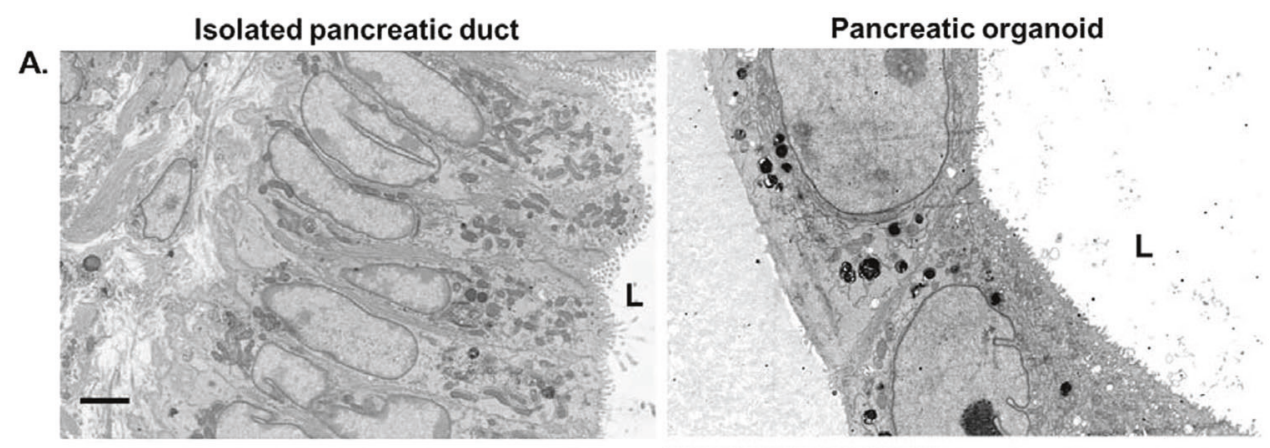

B.
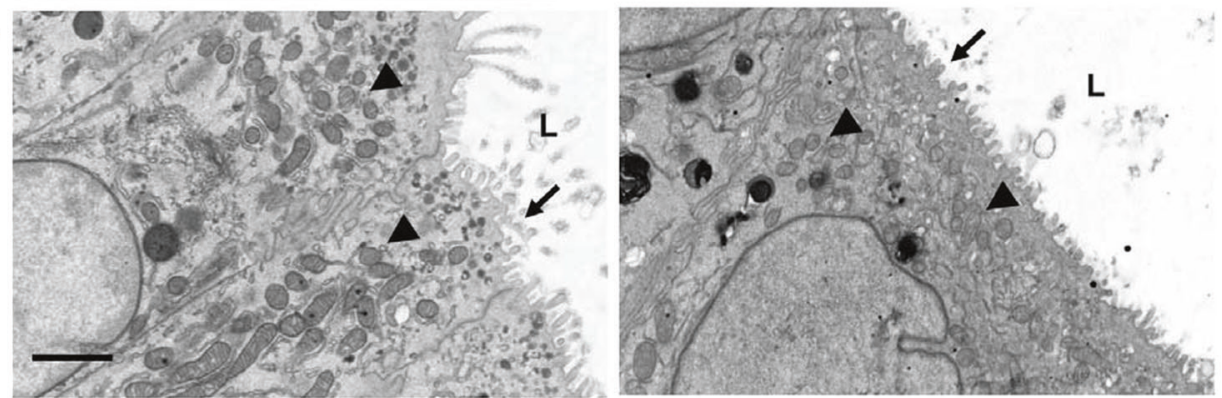

C.
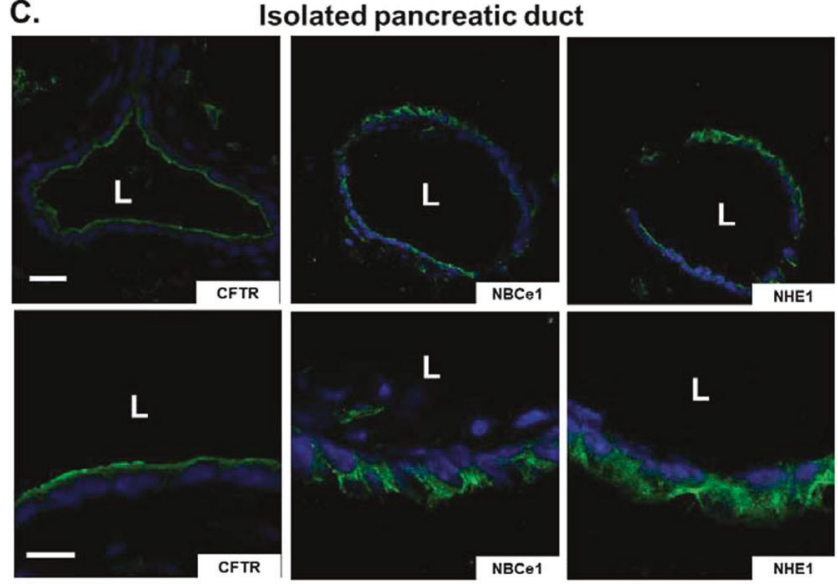

Fig. 2 Morphology and apical-basal polarity of isolated ducts and pancreatic organoids. Representative scanning electron microscope images show the ultrastructure of epithelial cells in isolated ducts and in pancreatic organoids. Brush border was observed on the apical membrane in both samples (arrows), whereas the majority of the mitochondria were located in the apical region of the cells (arrowheads) both in organoids and isolated ducts. L: lumen; scale bars: $2 \mu \mathrm{m}$

nonstimulated control level further indicating that the measured $\mathrm{Cl}^{-}$were due to the activity of CFTR. These results are consistent with our current knowledge of CFTR activity and regulation and thus this technique may be a powerful toolkit for researchers studying CFTR activity in $3 \mathrm{D}$ cultures.

We also utilized this technique to measure the activity of NKCC1 in isolated ducts and pancreatic organoids. As shown in Fig. 4c. the administration of $100 \mu \mathrm{M}$ Bumetanide (an NKCC1 inhibitor) decreased the $\left[\mathrm{Cl}^{-}\right]_{\mathrm{i}}$ suggesting an NKCC1-dependent basolateral $\mathrm{Cl}^{-}$uptake in ductal fragments and pancreatic organoids.

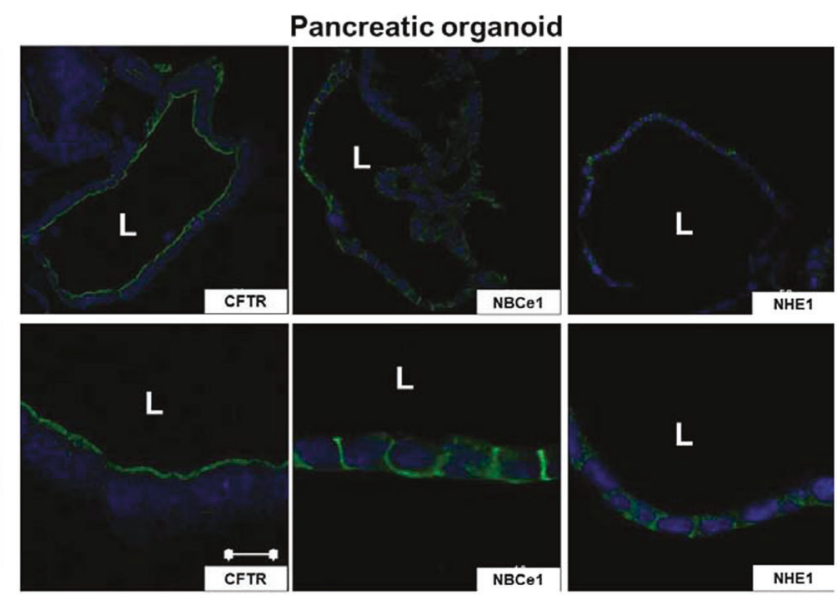

in lower (a) $1 \mu \mathrm{m}$ in higher magnification (b). c Representative confocal images demonstrate the polarized expression of proteins in epithelial cells. NHE1 and NBCe1 are expressed on the basolateral, whereas CFTR is expressed exclusively on the apical membrane. L: lumen; scale bars: $20 \mu \mathrm{m}$ in lower (upper panel), $10 \mu \mathrm{m}$ in higher magnification (lower panel)

\section{Basolateral $\mathrm{Na}^{+}$dependent $\mathrm{HCO}_{3}{ }^{-}$uptake in pancreatic organoids}

To compare the activity of basolateral $\mathrm{Na}^{+}$-dependent $\mathrm{HCO}_{3}{ }^{-}$uptake in primary pancreatic ductal fragments and pancreatic OCs, we applied the above described $\mathrm{NH}_{4} \mathrm{Cl}$ administration in $\mathrm{Na}^{+}$-free $\mathrm{HCO}_{3}{ }^{-} / \mathrm{CO}_{2}$-buffered solution. Under these conditions the recovery from acidosis was almost completely abolished confirming that this process strongly depends on the extracellular $\mathrm{Na}^{+}$and suggesting the potential role of NHE1 and NBCe1 in the process (Fig. 5a). To characterize the contribution of each 

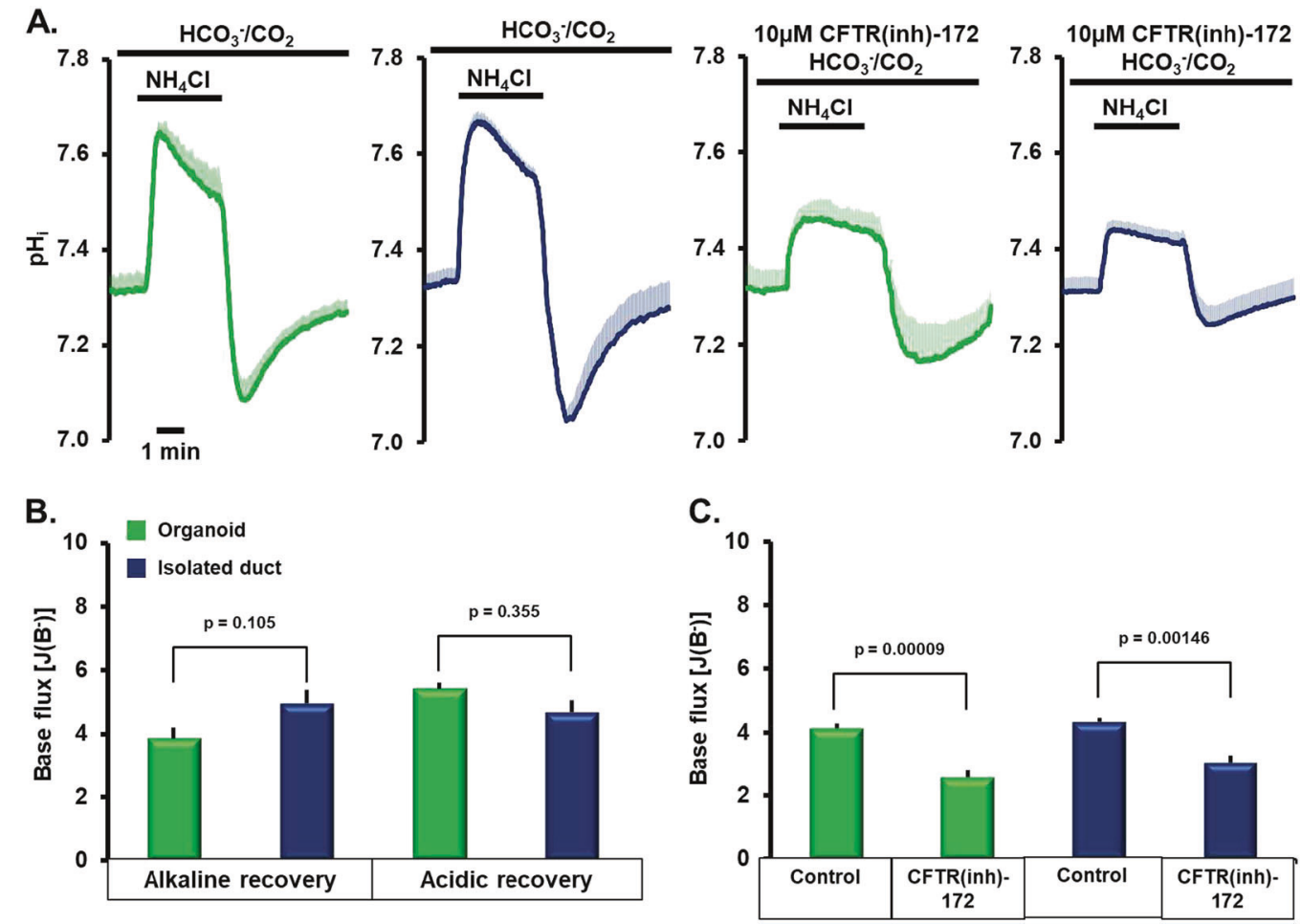

Fig. 3 Comparison of $\mathrm{HCO}_{3}{ }^{-}$secretion in isolated ducts and pancreatic organoids. a Average $\mathrm{pH}_{\mathrm{i}}$ traces of 4-6 experiments for each conditions. Pancreatic ducts or organoids were perfused with $\mathrm{HCO}_{3}$ - $/ \mathrm{CO}_{2}$-buffered extracellular solution and intracellular alkalization was achieved by $20 \mathrm{mM} \mathrm{NH}_{4} \mathrm{Cl}$ administration in the absence or presence

transporter in more details, we applied another protocol and specific inhibitors of NHE1 and NBCe1 (Supplementary Fig. 7B). During these series of experiments the standard HEPES was switched to $\mathrm{HCO}_{3}{ }^{-} / \mathrm{CO}_{2}$-buffered solution triggering a rapid drop in $\mathrm{pH}_{\mathrm{i}}$ due to the influx and intracellular conversion of $\mathrm{CO}_{2}$ to carbonic acid and its dissociation to $\mathrm{HCO}_{3}{ }^{-}$and $\mathrm{H}^{+}$. In the presence of extracellular $\mathrm{Na}^{+}$the $\mathrm{pH}_{\mathrm{i}}$ is restored to the resting level by NHE1 and NBCe1. As the average traces of individual experiments (Fig. $5 \mathrm{~b}, \mathrm{c}$ ) and the calculated base flux and $\Delta\left(\mathrm{pH}_{\mathrm{i}}\right)_{\max }$ (Fig. 5d, e) demonstrate, both primary ducts and pancreatic OCs showed similar responses to the specific inhibition of NHE1 (10 $\mu$ M EIPA) and NBCe1 (10 $\mu$ M S0859). In both cases the inhibition of NHE1 caused a higher decrease in the calculated base flux $(79.01 \%$ in OC and $70.62 \%$ in ducts) compared with the inhibition of NBCe1 $(60.82 \%$ in $\mathrm{OC}$ and $53.32 \%$ in ducts). The combined inhibition of NHE1 and NBCe1 did not decrease the basolateral $\mathrm{Na}^{+}$ dependent $\mathrm{HCO}_{3}{ }^{-}$uptake further.

\section{Intracellular $\mathrm{Ca}^{2+}$ signaling in pancreatic organoids}

In nonexcitable secretory epithelial cells, intracellular $\mathrm{Ca}^{2+}$ signaling is one of the major signal transduction pathways. Moreover, we and others have shown that changes of

of CFTR(inh)-172. Bar charts of the calculated base fluxes of $\mathrm{HCO}_{3}{ }^{-}$. Comparison of alkaline and acidic recovery, as representation of the apical and basolateral transport activities, showed no difference in primary ducts vs pancreatic organoids (b). CFTR inhibition markedly decreased alkaline recovery in each experiments (c)

intracellular $\mathrm{Ca}^{2+}$ concentration regulates ion secretion in physiology [23] and impairs transport functions via complex mechanisms in pathology [10]. Therefore, we also compared $\mathrm{Ca}^{2+}$ signaling in primary pancreatic ducts and in OCs. First, we used two $\mathrm{Ca}^{2+}$ mobilizing agonists (ATP and carbachol) that release $\mathrm{Ca}^{2+}$ from the endoplasmic reticulum (ER) $\mathrm{Ca}^{2+}$ stores. We detected that both agonists induced peak-plateau type $\mathrm{Ca}^{2+}$ elevation in the tested concentrations (Fig. 6a). These signals showed no significant differences in the maximal response (Fig. 6c). We also compared the store operated $\mathrm{Ca}^{2+}$ entry caused by the ER store depletion (Fig. 6b). Using this assay, we found that the $\mathrm{ER} \mathrm{Ca}^{2+}$ release induced by $25 \mu \mathrm{M}$ cyclopiazonic acid was significantly higher in isolated ducts, whereas the $\mathrm{Ca}^{2+}$ influx was significantly higher in OCs (Fig. 6d). These observations need further investigation to determine the biological relevance of this phenomena.

\section{Measurement of intraluminal $\mathrm{pH}$ in pancreatic organoids}

As intraluminal $\mathrm{pH}$ has a major physiological relevance we developed a new technique to follow its changes in response to various treatments. First, we used SNARF-1 as a control to monitor intracellular $\mathrm{pH}$ changes with confocal 

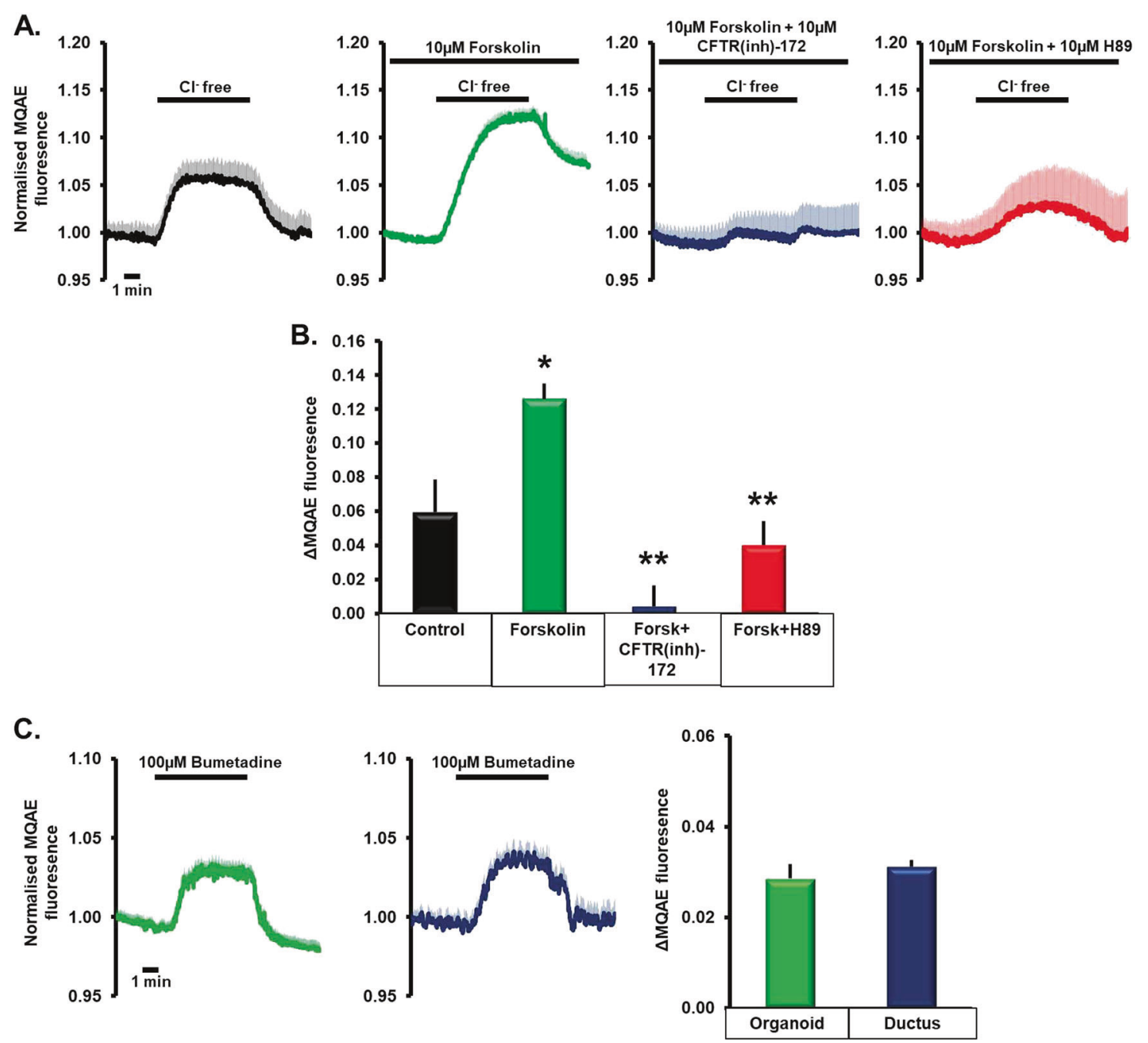

Fig. 4 Measurement of CFTR and NKCC1 activities in pancreatic organoids using $\mathrm{Cl}^{-}$sensitive fluorescent dye. a Average traces of intracellular $\mathrm{Cl}^{-}$levels of 4-6 experiments for each conditions. Pancreatic organoids were perfused with $\mathrm{HCO}_{3}{ }^{-} / \mathrm{CO}_{2}$ buffered extracellular solution. Removal of extracellular $\mathrm{Cl}^{-}$induced a decrease in intracellular $\mathrm{Cl}^{-}$levels (reflected by an increase in fluorescent intensity) due to the activity of CFTR. b Bar charts of the maximal fluorescent intensity changes. $10 \mu \mathrm{M}$ forskolin significantly increased,

microscope (Fig. 7a and Supplementary Fig. 8). As demonstrated, this technique can be used to follow dynamic $\mathrm{pH}$ changes. In the next step a glass needle was used to inject dextran conjugated SNARF-1 into the lumen of the organoids (Fig. 7b). The injected dye was trapped in the lumen and was not taken up by the epithelial cells. Administration of $\mathrm{NH}_{4} \mathrm{Cl}$ in HEPES-buffered solution caused a moderate increase in the intraluminal $\mathrm{pH}$ which could be attributed to the diffusion of $\mathrm{NH}_{3}$ into the organoid lumen (Fig. 7c). In contrast, $\mathrm{NH}_{4} \mathrm{Cl}$ in $\mathrm{HCO}_{3}{ }^{-} / \mathrm{CO}_{2}$-buffered solution triggered a rapid and notable elevation of intraluminal $\mathrm{pH}$ due to the efflux of $\mathrm{HCO}_{3}{ }^{-}$to the lumen. This elevation was completely abolished by $10 \mu \mathrm{M}$ CFTR whereas $10 \mu \mathrm{M}$ CFTR(inh)-172 and H-89 significantly impaired cAMP-stimulated CFTR activity in pancreatic organoids. $* p<0.05$ vs Control, $* * p<0.05$ vs Forskolin. c Average traces of intracellular $\mathrm{Cl}^{-}$levels and bar charts of NKCC1 activity. To measure NKCC1 activity, organoids and ductal fragments were treated with bumetanide in $\mathrm{HCO}_{3}{ }^{-} / \mathrm{CO}_{2}$-buffered extracellular solution in organoids and ductal fragment

(inh)-172 administration suggesting the major role of CFTR in this process.

\section{Discussion}

OCs have recently emerged as promising ex vivo models of tissue development, physiology and pathophysiology. Reports suggested that cells in OCs maintain tissue specific gene expression, cell morphology and function and may represent features of malignant diseases. Although organoids are used in an increasing number of studies, we only have limited experimental data about their physiological 
A.
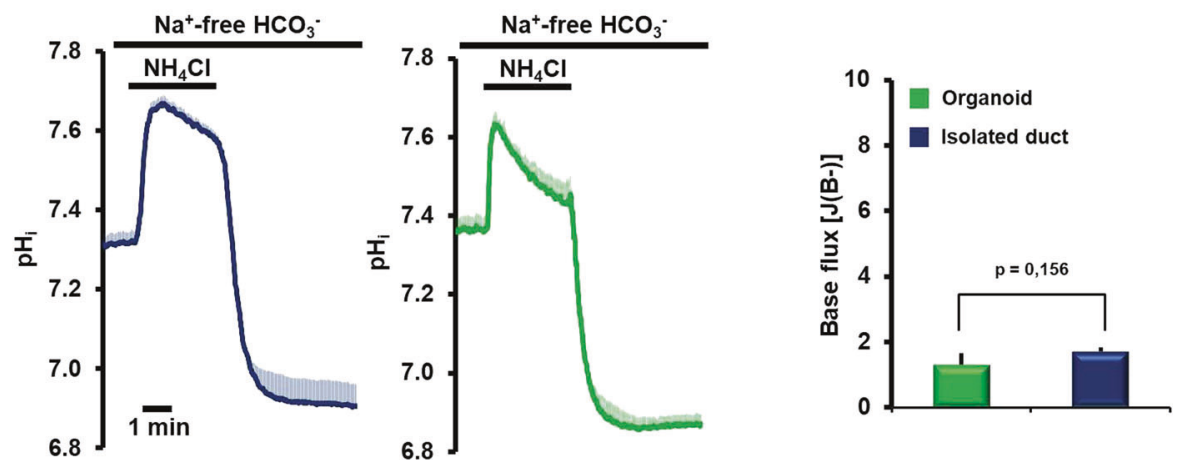

B.
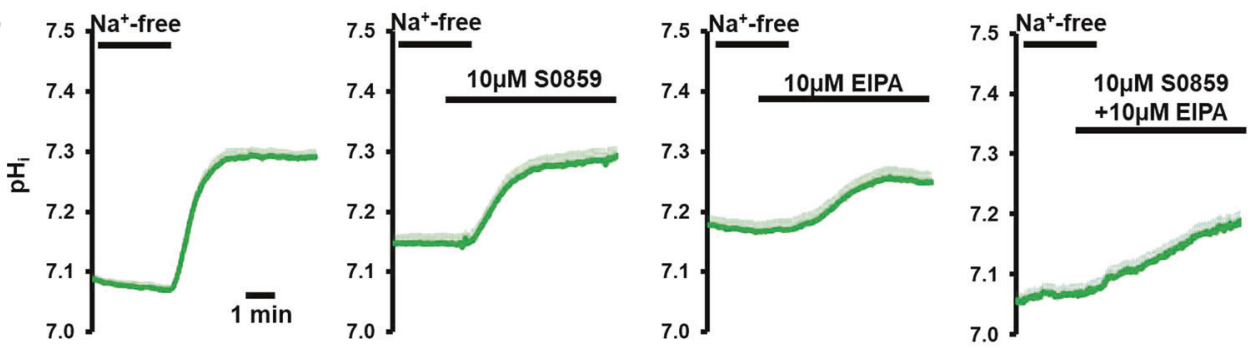

C.
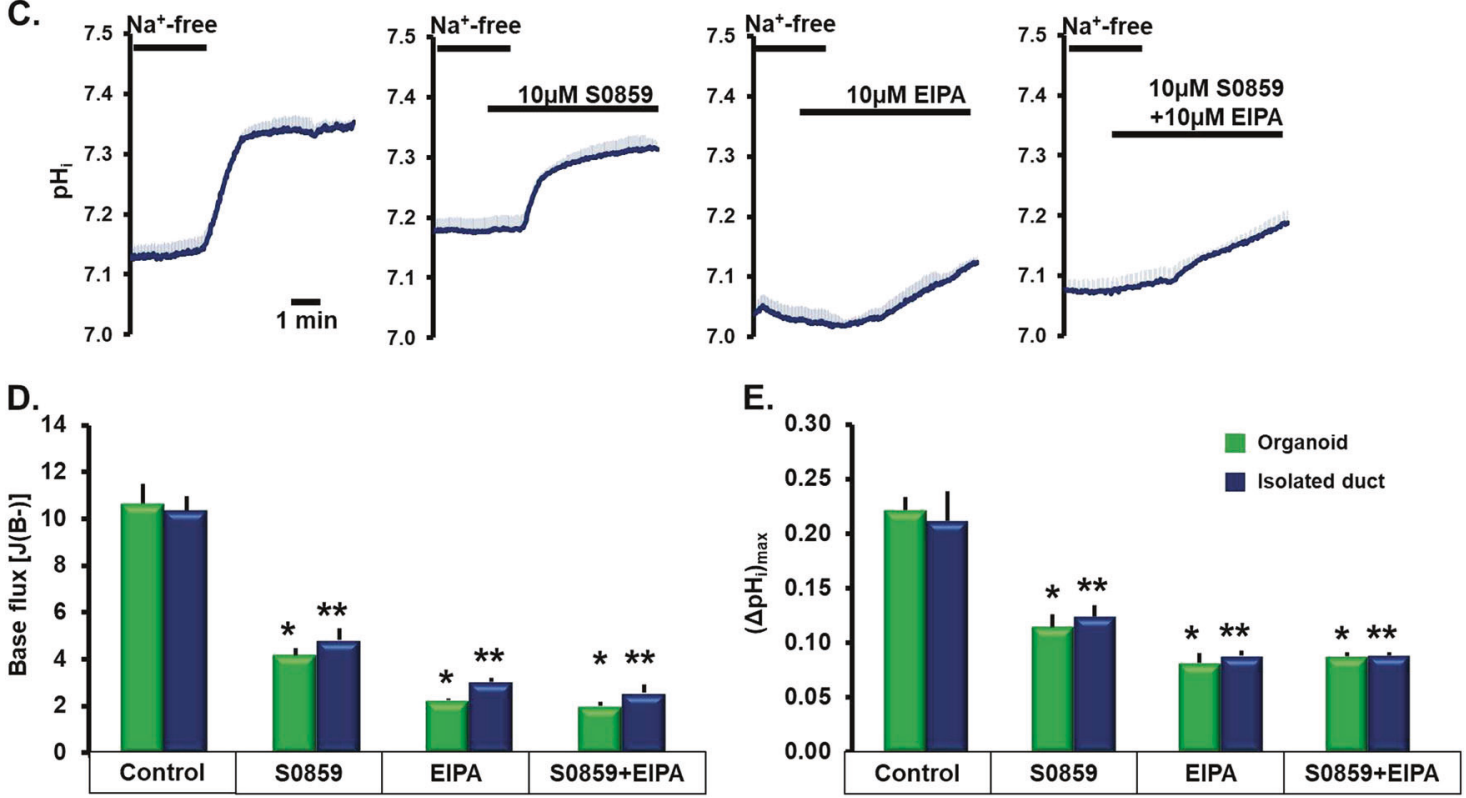

Fig. 5 Comparison of basolateral $\mathrm{HCO}_{3}{ }^{-}$uptake in isolated ducts and pancreatic organoids. a Average $\mathrm{pH}_{\mathrm{i}}$ traces and bar charts from 4-6 experiments demonstrate that basolateral $\mathrm{Na}^{+}$removal almost completely abolished the recovery from intracellular acidosis. Average $\mathrm{pH}_{\mathrm{i}}$ traces showing the effect of different inhibitors on the basolateral $\mathrm{Na}^{+}$ dependent $\mathrm{HCO}_{3}{ }^{-}$uptake in $\mathrm{HCO}_{3}{ }^{-} / \mathrm{CO}_{2}$ buffered extracellular solution in pancreatic organoids (b) and in isolated ducts (c) (4-6

experiments for each conditions). Bar charts of calculated base flux (d) and maximal $\mathrm{pH}$ changes (e) show that inhibition of NBCe1 (S0859) and/or NHE1 (EIPA) activity significantly decreased the recovery. No significant differences were detected between isolated ducts and organoids. $* p<0.05$ vs Organoid Control; $* * p<0.05$ vs Isolated duct Control

relevance, especially in case of pancreatic OCs. Therefore, in this manuscript we provide side-by-side comparison of gene expression, cell morphology and function of pancreatic ductal epithelial cells derived from primary isolated ductal fragments and of pancreatic OCs.

Ion (especially $\mathrm{HCO}_{3}{ }^{-}$) and fluid secretion is the primary function of the pancreatic ductal epithelia, which is obtained

by the interaction of the electrogenic SLC26 $66 \mathrm{Cl}^{-} / \mathrm{HCO}_{3}{ }^{-}$ exchanger and the $\mathrm{CFTR}^{-}{ }^{-}$channel $[1,24]$. Due to the molecular interaction between the two proteins the ductal cells are able to secrete and maintain $140 \mathrm{mM}$ intraluminal $\mathrm{HCO}_{3}{ }^{-}$concentration $(\sim 5-6$ fold higher than the intracellular) [25]. The current model suggests that in the proximal ducts CFTR provides the extracellular $\mathrm{Cl}^{-}$for 

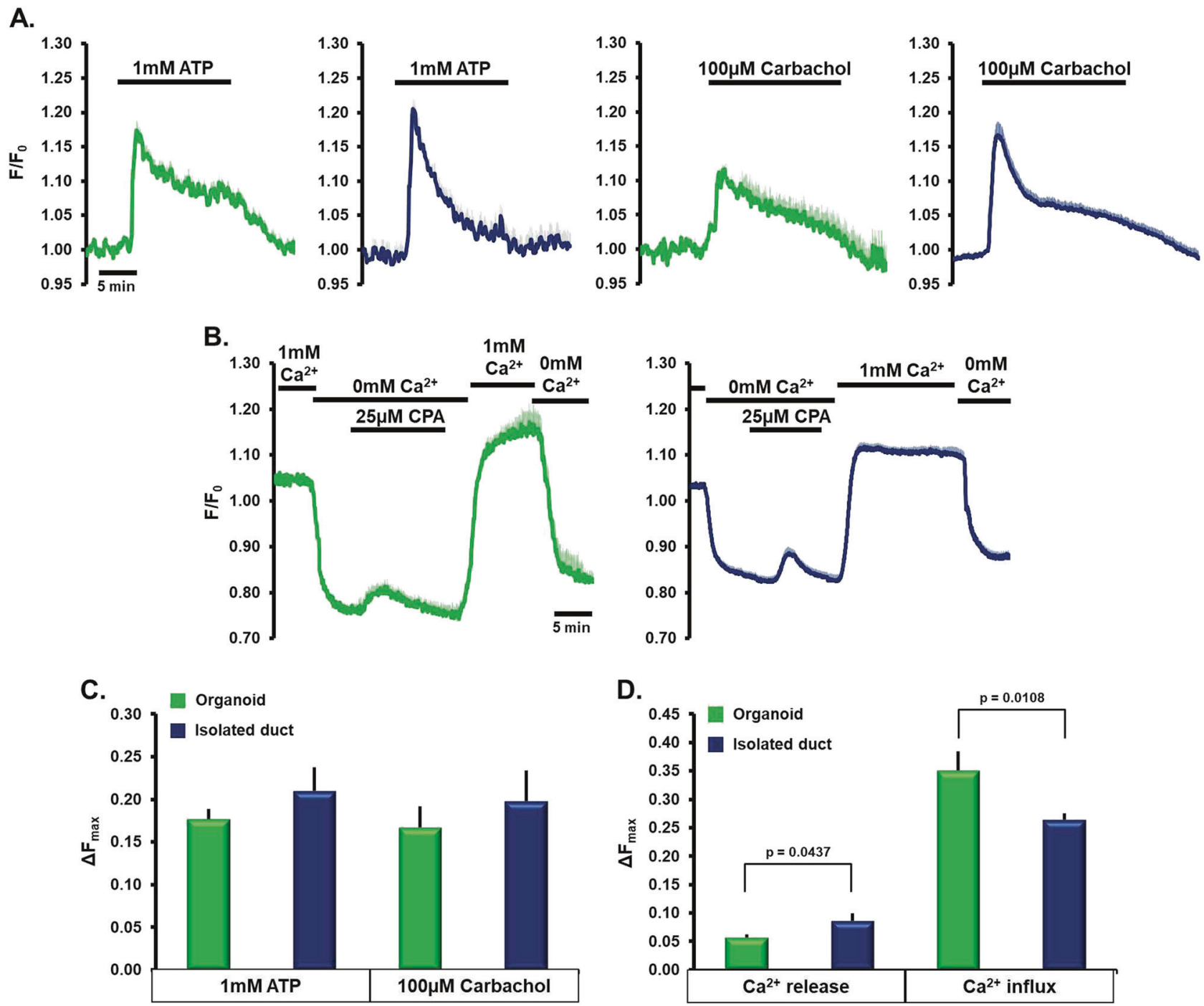

Fig. 6 Intracellular $\mathrm{Ca}^{2+}$ signaling in isolated pancreatic ducts and organoids. a Average traces of 4-6 experiments demonstrating the effect of $1 \mathrm{mM}$ ATP, or $100 \mu \mathrm{M}$ carbachol on pancreatic epithelial cells. Both agonists induced peak-plateau $\mathrm{Ca}^{2+}$ signals. b $\mathrm{Ca}^{2+}$ influx in pancreatic ducts and OCs (average traces of 4-6 experiments). ER

the $\mathrm{Cl}^{-} / \mathrm{HCO}_{3}{ }^{-}$exchange of SLC26A6. However, in the distal pancreatic ducts, the anion exchange of SLC26A6 is not possible to maintain due to the very low luminal and intracellular $\mathrm{Cl}^{-}$concentration. Under these conditions CFTR permeability is switched by With-No-Lysine (WNK)/STE20/SPS1-related proline/alanine-rich kinase (SPAK) kinases in favor of $\mathrm{HCO}_{3}{ }^{-}$[26]. On the opposite site, the accumulation of the $\mathrm{HCO}_{3}{ }^{-}$across the basolateral membrane is mediated by the electrogenic NBCe1. Another factor in this process is the passive diffusion of $\mathrm{CO}_{2}$ through the membrane followed by the carbonic anhydrasemediated conversion of $\mathrm{CO}_{2}$ to $\mathrm{HCO}_{3}{ }^{-}$and $\mathrm{H}^{+}$[27]. In addition to these, NHE1 maintains the $\mathrm{pH}_{\mathrm{i}}$ by transporting excess $\mathrm{H}^{+}$from the cells. Therefore, first we analyzed the expression of genes encoding these ion channels and

$\mathrm{Ca}^{2+}$ release induced by $25 \mu \mathrm{M}$ cyclopiazonic acid $(\mathrm{CPA})$ and $\mathrm{Ca}^{2+}$ influx was measured by the maximal response to $\mathrm{HCO}_{3}{ }^{-} / \mathrm{CO}_{2}$ buffered extracellular solution readdition of $\mathrm{Ca}^{2+}$. Summary of the maximal $\mathrm{Ca}^{2}$ ${ }^{+}$responses to agonist stimulation (c) and $\mathrm{ER} \mathrm{Ca}^{2+}$ release (first two columns) and $\mathrm{Ca}^{2+}$ influx (second two columns) (d)

transporters in isolated ducts and OCs. Our results confirmed the expression of these genes in primary mouse ductal fragments and also in pancreatic OCs. Moreover, the expression of Atp12a (encoding nongastric $\mathrm{H}^{+} / \mathrm{K}^{+}$ ATPase); Kcnmal (encoding BK channel), Slc26a3, and $N k c c l$ overlapped in the two types of samples. We also found that four members of the voltage-gated potassium channel subfamily Kcna1, Kcna2, Kcnd3, and Kcnhl are expressed in pancreatic epithelial cells, which have not been described earlier. In addition, we showed the expression of two voltage-gated $\mathrm{Cl}^{-}$channels: $C l c n 1$ and $C l c n 3$ that were not suggested earlier. Transcription of Clcn3 has only been described in pancreatic $\beta$-cells, where it is localized on insulin granules and play a role in insulin processing and secretion through regulation of granular acidification [28]. 

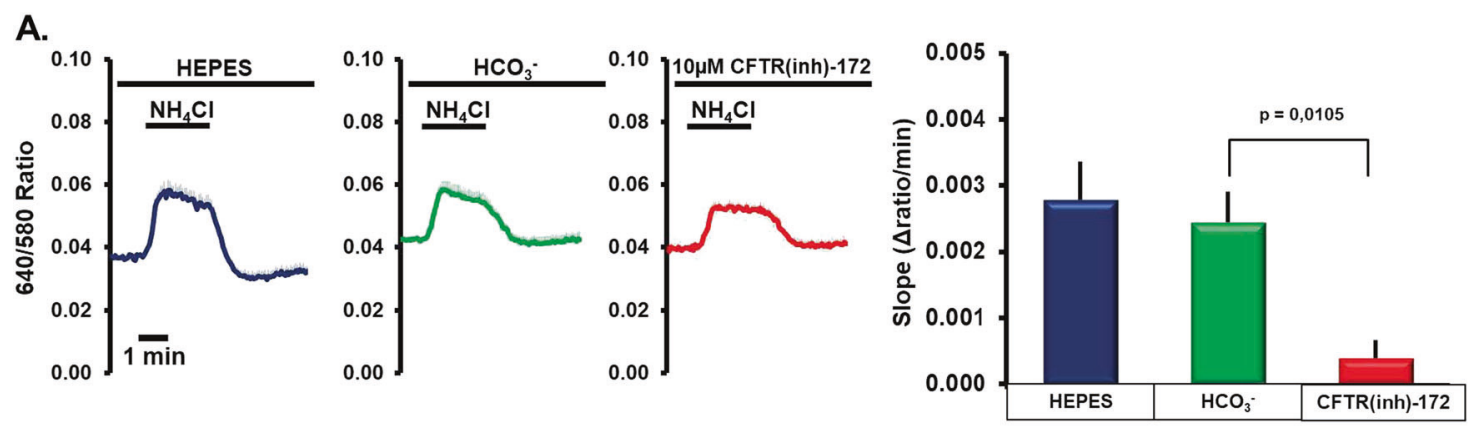

B.
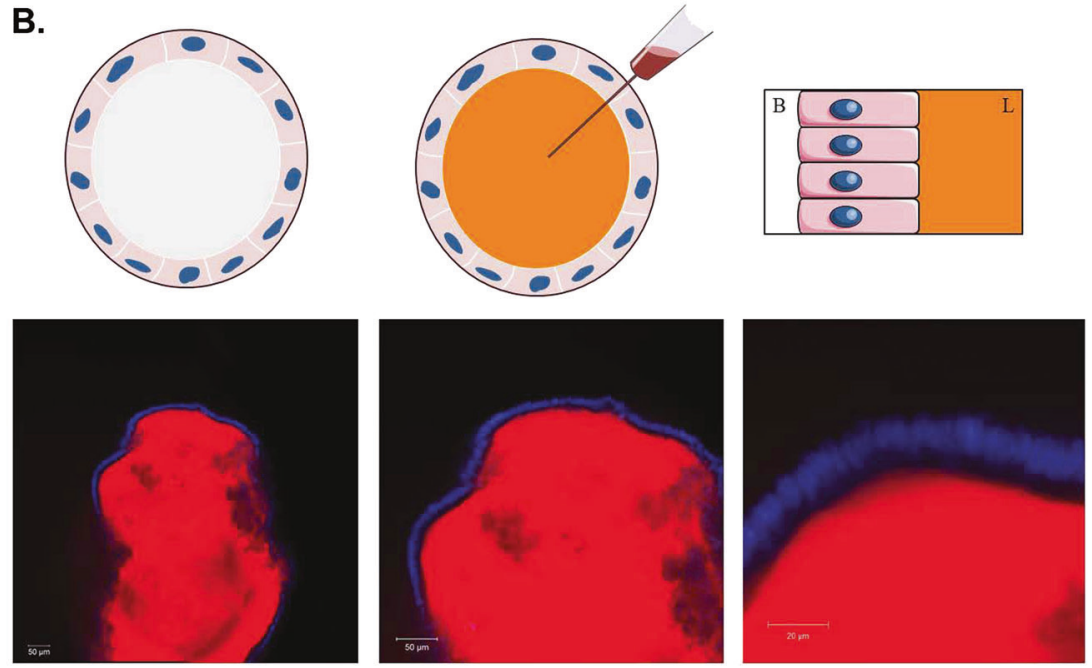
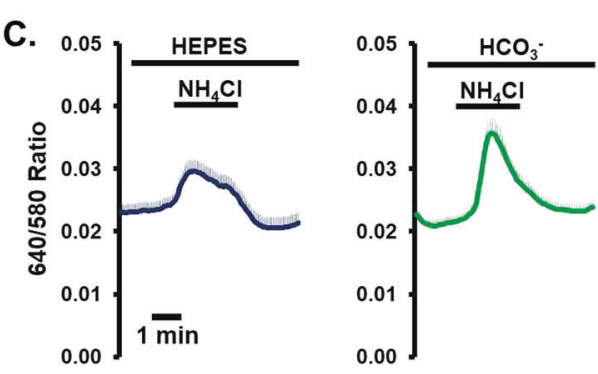

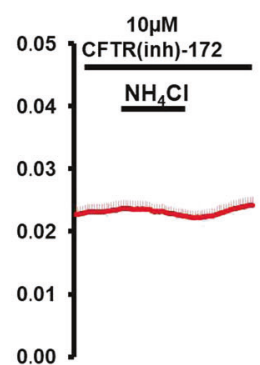

Fig. 7 Measurement of intracellular and intraluminal $\mathrm{pH}$ in pancreatic organoids. a Measurement of intracellular $\mathrm{pH}\left(\mathrm{pH}_{\mathrm{i}}\right)$ with SNARF-1. Average traces and bar charts of 4-6 experiments. Similarly to the earlier results $\mathrm{NH}_{4} \mathrm{Cl}$ caused intracellular alkalosis followed by a slow regeneration, which was inhibited by CFTR(inh)-172. b Schematic representation of the administration of SNARF1-dextrane to the lumen of the organoids and confocal images of the SNARF1-dextrane loaded

Moreover, our results showed that Enac and Anol are expressed in both isolated primary ductal fragments as well as pancreatic OC. The relatively strong expression of Enac in pancreatic epithelia is somewhat unexpected since earlier studies were not able to demonstrate functional activity of $\mathrm{ENaC}$ in rat pancreatic ducts [29] and according to the current hypothesis $\mathrm{ENaC}$ is not expressed and has no role in exocrine pancreatic epithelial cells [1]. In the next step, we compared the morphology of the isolated ducts and OCs with a special focus on apical-basal polarity. The ultrastructure of the epithelial cells in the two samples showed organoids. As demonstrated, SNARF1 was restricted to the intraluminal space and no intracellular dye uptake could be observed. c Average traces of intraluminal $\mathrm{pH}$ changes. Administration of $\mathrm{NH}_{4} \mathrm{Cl}$ in HEPES-, or in $\mathrm{HCO}_{3}{ }^{-} / \mathrm{CO}_{2}$-buffered solution triggered a rapid elevation of intraluminal $\mathrm{pH}$ due to the efflux of $\mathrm{HCO}_{3}{ }^{-}$to the lumen, which was completely abolished by $10 \mu \mathrm{M}$ CFTR(inh)-172

no major difference and the OCs epithelial cells represented the same features-increased apical density of mitochondria, brush border on the apical membrane-like primary ductal cells. Importantly, the distribution of proteins showed similar pattern in cross sections of organoids and isolated ducts. We confirmed that CFTR is expressed exclusively on the apical, whereas NHE1 and NBCe1 were found on the basolateral membrane, which is concordant to the current literature $[1,4]$. Taken together, our results demonstrated a complete overlap of gene expression and morphology of isolated ductal fragments and pancreatic OCs and more 
importantly the use of OCs can ensure that results are not derived from heterogeneous tissue fragments but from primary epithelial cell monolayers. Notably, these results also suggest that the exocrine pancreatic ductal secretion may be far more complicated than the currently used models suggest [30]. Further analysis will be needed to clarify the functional relevance of these results (especially the role of $\mathrm{ENaC}, \mathrm{CCls}$, and $\mathrm{K}^{+}$channels) and special attention should be paid to species dependent alterations in expression and eventually in protein function. However, if protein expression and function confirms these findings, our results might indicate the need of revision of the current model of pancreatic ductal secretion.

As mentioned earlier, only a limited number of studies have been published about the functional analysis of organoids. Recently Foulke-Abel et al. used human intestinal crypt-derived enteroids to investigate their functional relevance to ion transport physiology and pathophysiology [31]. Using undifferentiated and differentiated enteroids, they demonstrated that these organoids show similar apical-basal polarity to the human small intestine enterocytes and express functionally active NHE3, which is the most prominent transporter in this cell type. Organoid swelling was inhibited by inhibitors of CFTR, NKCC, and NHE3. Whereas intracellular acidification caused by forskolin administration in $\mathrm{HCO}_{3} / \mathrm{CO}_{2}{ }^{-}$buffered solution was created by CFTR and electrogenic NBC1. In 2018, O'Malley et al. reported the establishment of a culture system of differentiated pancreatic ductal epithelial cells in a polarized monolayer [32]. In this 2D air-liquid interface culture system, cells were grown on semipermeable filters and were reported to develop epithelial cell morphology. Short circuit current and extracellular $\mathrm{pH}$ measurements revealed that these cells respond to increase of intracellular cAMP and express functionally active CFTR channels. Although, the culture system could overcome some limitations of isolated ductal fragments (such as the presence of contaminating fibroblasts) and it can be used for short circuit current measurements, it still possesses the drawbacks of the 2D culture systems [33], whereas maintenance of this culture seems to be tedious and less efficient compared with 3D organoid cultures. Although functional data are limited, the described results highlighted that organoids might be a powerful ex vivo system to represent original tissue morphology and functions and could be used to model pancreatic ductal secretory functions in physiology and pathology. Therefore, in this study we performed functional analysis of pancreatic OCs and compared them with the well-studied isolated ductal fragments used as a reference point. Measurements of apical $\mathrm{HCO}_{3}{ }^{-}$secretion and basolateral $\mathrm{HCO}_{3}{ }^{-}$ uptake were highly comparable in OCs and primary ducts. In addition, the activities of other ion transport processes mediated by NHE1, or NKCC1 were similar in the two systems. Finally, the $\mathrm{Ca}^{2+}$ signaling, which is one of the major signal transduction pathways in the pancreatic ductal epithelia [34], showed similar characteristics in OCs further supporting the functional equality of pancreatic organoids with the primary ductal system.

As mentioned in the introduction, the intraductal $\mathrm{pH}$ has a major importance in the exocrine pancreatic physiology. Earlier studies showed that protons are coreleased during exocytosis of digestive enzymes thus causing significant intraluminal acidosis, which has to be compensated by ductal cells to avoid intrapancreatic trypsinogen activation [35] and the development of AP [36]. This was further confirmed in patients, where intraductal $\mathrm{pH}$ in acute biliary pancreatitis was significantly decreased compared with the controls $(6.97 \pm 0.13$ vs $7.79 \pm 0.20)$ [37]. Therefore, we developed a technique that utilizes dextran conjugated $\mathrm{pH}$ sensitive fluorescent dye SNARF1 to monitor $\mathrm{pH}$ changes in the lumen of the organoids. Using this technique, we were able to follow the $\mathrm{pH}$ elevation induced by $\mathrm{NH}_{4} \mathrm{Cl}$ administration, which was completely blocked by CFTR inhibition.

Patient-derived pancreatic tumor organoids have been successfully used for disease modeling and to predict response to anticancer therapy $[17,30,31]$. In another study human pluripotent stem cells were used to generate acinar/ ductal organoids to model cystic fibrosis [38]. In experimental setup that was more focused on organoid function Dekkers et al. used patient-derived rectal organoids to measure CFTR activity and predict response to CFTR corrector and/or potentiator therapy [39]. They used FIS which is currently the state-of-the-art technique to measure CFTR-dependent ion and fluid secretion [22]. Whereas FIS is relatively simple and robust method that correlates well with the individual response to cystic fibrosis treatment, it also might have some potential limitations. During forskolin stimulation the secreted fluid expands the lumen and the increasing intraluminal pressure prevents water efflux that might therefore not follow the ion current linearly. In addition, the increased tension might activate the mechanoreceptors (such as Piezo1) in the apical membrane of epithelial cells [40]. This shall not be a problem in samples with CFTR expression defects, where the initial fluid secretion is marginal [41]. However in wild type pancreatic organoids FIS leads to a relatively rapid rupture of the organoids (data not shown). Therefore instead of measuring the relative luminal volume of the organoids, we utilized a $\left[\mathrm{Cl}^{-}\right]_{\mathrm{i}}$ sensitive fluorescent indicator to follow $\mathrm{Cl}^{-}$ movements in pancreatic OCs [42]. Our results with this technique are consistent with the literature data since forskolin significantly enhanced, whereas CFTR, or PKA inhibition markedly decreased the increase of fluorescent signal. Therefore this technique could be potentially capitalized in pancreatic physiology research and in drug screening studies to identify compounds that improve exocrine pancreatic ductal secretion. 
Taken together, after thorough analysis, we have demonstrated that epithelial cells in OCs remarkably correspond with the primary ductal epithelia. Our results confirmed that pancreatic OCs could be a relevant, highly reproducible ex vivo model system with increased throughput to study pancreatic secretory physiology and pathology and thus could be a potential solution for an unmet need in pancreatic research.

Acknowledgements The research was supported by funding from the Hungarian National Research, Development and Innovation Office (PD115974 and GINOP-2.3.2-15-2016-00048 to JM, PD116553 to PP, K119938 to RZ), the Ministry of Human Capacities (EFOP 3.6.216-2017-00006 to JM), Bolyai Research Fellowship (BO/00440/16/5 to $\mathrm{JM}, \mathrm{BO} / 00569 / 17$ to $\mathrm{PP}$ ), the Hungarian Academy of Sciences (LP2017-18/2017 to JM), by the National Excellence Program (20391-3/2018/FEKUSTRAT to JM), by the New National Excellence Program of the Ministry of Human Capacities (UNKP-18-4-SZTE-85 to PP, UNKP-18-3-I-SZTE-66 to MT) and EFOP 3.6.3-VEKOP-162017-00009 to MT. The authors are grateful to David Tuveson for providing the protocol of pancreatic organoid generation and to Hans Clevers for generously sharing the Noggin-expressing cell line with us.

\section{Compliance with ethical standards}

Conflict of interest The authors declare that they have no conflict of interest.

Publisher's note: Springer Nature remains neutral with regard to jurisdictional claims in published maps and institutional affiliations.

\section{References}

1. Lee MG, Ohana E, Park HW, Yang D, Muallem S. Molecular mechanism of pancreatic and salivary gland fluid and $\mathrm{HCO}_{3}$ secretion. Physiol Rev. 2012;92:39-74.

2. Hegyi P, Pandol S, Venglovecz V, Rakonczay Z Jr. The acinarductal tango in the pathogenesis of acute pancreatitis. Gut. 2011;60:544-52.

3. Pallagi P, Venglovecz V, Rakonczay Z Jr., Borka K, Korompay A, et al. Trypsin reduces pancreatic ductal bicarbonate secretion by inhibiting CFTR $\mathrm{Cl}(-)$ channels and luminal anion exchangers. Gastroenterology. 2011;141:2228-39 e6.

4. Zeng M, Szymczak M, Ahuja M, Zheng C, Yin H, Swaim W, et al. Restoration of CFTR activity in ducts rescues acinar cell function and reduces inflammation in pancreatic and salivary glands of mice. Gastroenterology. 2017;153:1148-59.

5. Pallagi P, Balla Z, Singh AK, Dosa S, Ivanyi B, Kukor Z, et al. The role of pancreatic ductal secretion in protection against acute pancreatitis in mice*. Crit Care Med. 2014;42:e177-88.

6. Maleth J, Balazs A, Pallagi P, Balla Z, Kui B, Katona M, et al. Alcohol disrupts levels and function of the cystic fibrosis transmembrane conductance regulator to promote development of pancreatitis. Gastroenterology. 2015;148:427-39 e16.

7. Hegyi P, Wilschanski M, Muallem S, Lukacs GL, Sahin-Toth M, Uc A, et al. CFTR: a new horizon in the pathomechanism and treatment of pancreatitis. Rev Physiol, Biochem Pharmacol. 2016;170:37-66.

8. Argent BE, Arkle S, Cullen MJ, Green R. Morphological, biochemical and secretory studies on rat pancreatic ducts maintained in tissue culture. Q J Exp Physiol. 1986;71:633-48.
9. Hegyi P, Gray MA, Argent BE. Substance P inhibits bicarbonate secretion from guinea pig pancreatic ducts by modulating an anion exchanger. Am J Physiol Cell Physiol. 2003;285:C268-76.

10. Maleth J, Venglovecz V, Razga Z, Tiszlavicz L, Rakonczay Z Jr., Hegyi P. Non-conjugated chenodeoxycholate induces severe mitochondrial damage and inhibits bicarbonate transport in pancreatic duct cells. Gut. 2011;60:136-8.

11. Sato T, Stange DE, Ferrante M, Vries RG, Van Es JH, Van den Brink $\mathrm{S}$, et al. Long-term expansion of epithelial organoids from human colon, adenoma, adenocarcinoma, and Barrett's epithelium. Gastroenterology. 2011;141:1762-72.

12. Clevers H. Modeling development and disease with organoids. Cell. 2016;165:1586-97.

13. Nusse R, Clevers H. Wnt/beta-catenin signaling, disease, and emerging therapeutic modalities. Cell. 2017;169:985-99.

14. Kretzschmar K, Clevers H. Organoids: modeling development and the stem cell niche in a dish. Dev Cell. 2016;38:590-600.

15. Sato T, Vries RG, Snippert HJ, van de Wetering M, Barker N, Stange DE, et al. Single Lgr5 stem cells build crypt-villus structures in vitro without a mesenchymal niche. Nature. 2009;459:262-5.

16. Barker N, Huch M, Kujala P, van de Wetering M, Snippert HJ, van Es JH, et al. Lgr5(+ve) stem cells drive self-renewal in the stomach and build long-lived gastric units in vitro. Cell Stem Cell. 2010;6:25-36.

17. Huch M, Bonfanti P, Boj SF, Sato T, Loomans CJ, van de Wetering $\mathrm{M}$, et al. Unlimited in vitro expansion of adult bi-potent pancreas progenitors through the Lgr5/R-spondin axis. EMBO J. 2013;32:2708-21.

18. Simian M, Bissell MJ. Organoids: a historical perspective of thinking in three dimensions. J Cell Biol. 2017;216:31-40.

19. Dahl-Jensen SB, Yennek S, Flasse L, Larsen HL, Sever D, Karremore G, et al. Deconstructing the principles of ductal network formation in the pancreas. PLoS Biol. 2018;16:e2002842.

20. Boj SF, Hwang CI, Baker LA, Chio II, Engle DD, Corbo V, et al. Organoid models of human and mouse ductal pancreatic cancer. Cell. 2015;160:324-38.

21. Venglovecz V, Rakonczay Z Jr., Gray MA, Hegyi P. Potassium channels in pancreatic duct epithelial cells: their role, function and pathophysiological relevance. Pflugers Arch. 2015;467:625-40.

22. Dekkers JF, Berkers G, Kruisselbrink E, Vonk A, de Jonge HR, Janssens HM, et al. Characterizing responses to CFTR-modulating drugs using rectal organoids derived from subjects with cystic fibrosis. Sci Transl Med. 2016;8:344ra84.

23. Yang D, Li Q, So I, Huang CL, Ando H, Mizutani A, et al. IRBIT governs epithelial secretion in mice by antagonizing the WNK/ SPAK kinase pathway. J Clin Invest. 2011;121:956-65.

24. Maleth J, Hegyi P. Calcium signaling in pancreatic ductal epithelial cells: An old friend and a nasty enemy. Cell Calcium 2014;55:337-45.

25. Hong JH, Park S, Shcheynikov N, Muallem S. Mechanism and synergism in epithelial fluid and electrolyte secretion. Pflugers Arch. 2014;466:1487-99.

26. Park HW, Nam JH, Kim JY, Namkung W, Yoon JS, Lee JS, et al. Dynamic regulation of CFTR bicarbonate permeability by [Cl-]i and its role in pancreatic bicarbonate secretion. Gastroenterology. 2010;139:620-31.

27. Dyck WP, Hightower NC, Janowitz HD. Effect of acetazolamide on human pancreatic secretion. Gastroenterology. 1972;62:547-52.

28. Deriy LV, Gomez EA, Jacobson DA, Wang X, Hopson JA, Liu $\mathrm{XY}$, et al. The granular chloride channel ClC-3 is permissive for insulin secretion. Cell Metab. 2009;10:316-23.

29. Novak I, Hansen MR. Where have all the $\mathrm{Na}+$ channels gone? In search of functional $\mathrm{ENaC}$ in exocrine pancreas. Biochim Biophys Acta. 2002;1566:162-8. 
30. Yamaguchi M, Steward MC, Smallbone K, Sohma Y, Yamamoto A, Ko SB, et al. Bicarbonate-rich fluid secretion predicted by a computational model of guinea-pig pancreatic duct epithelium. $\mathbf{J}$ Physiol. 2017;595:1947-72.

31. Foulke-Abel J, In J, Yin J, Zachos NC, Kovbasnjuk O, Estes MK, et al. Human enteroids as a model of upper small intestinal ion transport physiology and pathophysiology. Gastroenterology. 2016;150:638-49 e8.

32. O'Malley Y, Rotti PG, Thornell IM, Vanegas Calderon OG, Febres-Aldana C, Durham K, et al. Development of a polarized pancreatic ductular cell epithelium for physiological studies. J Appl Physiol. 2018;125:97-106.

33. Horvath P, Aulner N, Bickle M, Davies AM, Nery ED, Ebner D, et al. Screening out irrelevant cell-based models of disease. Nat Rev Drug Discov. 2016;15:751-69.

34. Maleth J, Hegyi P. Calcium signaling in pancreatic ductal epithelial cells: an old friend and a nasty enemy. Cell Calcium. 2014;55:337-45.

35. Behrendorff N, Floetenmeyer M, Schwiening C, Thorn P. Protons released during pancreatic acinar cell secretion acidify the lumen and contribute to pancreatitis in mice. Gastroenterology. 2010;139:1711-20. 20 e1-5

36. Geisz A, Sahin-Toth M. A preclinical model of chronic pancreatitis driven by trypsinogen autoactivation. Nat Commun. 2018;9:5033.
37. Takacs T, Rosztoczy A, Maleth J, Rakonczay Z Jr., Hegyi P. Intraductal acidosis in acute biliary pancreatitis. Pancreatology. 2013;13:333-5.

38. Hohwieler M, Illing A, Hermann PC, Mayer T, Stockmann M, Perkhofer L, et al. Human pluripotent stem cell-derived acinar/ ductal organoids generate human pancreas upon orthotopic transplantation and allow disease modelling. Gut. 2017; 66:473-86

39. Dekkers JF, Wiegerinck CL, de Jonge HR, Bronsveld I, Janssens $\mathrm{HM}$, de Winter-de Groot KM, et al. A functional CFTR assay using primary cystic fibrosis intestinal organoids. Nat Med. 2013;19:939-45.

40. Romac JM, Shahid RA, Swain SM, Vigna SR, Liddle RA. Piezo1 is a mechanically activated ion channel and mediates pressure induced pancreatitis. Nat Commun. 2018;9:1715.

41. Boj SF, Vonk AM, Statia M, Su J, Vries RR, Beekman JM, et al. Forskolin-induced swelling in intestinal organoids: an in vitro assay for assessing drug response in cystic fibrosis patients. J Vis Exp. 2017.

42. Ko SB, Shcheynikov N, Choi JY, Luo X, Ishibashi K, Thomas PJ, et al. A molecular mechanism for aberrant CFTRdependent $\mathrm{HCO}(3)(-)$ transport in cystic fibrosis. EMBO J. 2002;21:5662-72. 